\title{
Management of Submacula Bleeding with Pneumatic Displacement
}

\author{
Shaelva Lassa Sabatini ${ }^{1 *}$, AK Ansyori ${ }^{1}$, Ramzi Amin ${ }^{1}$
}

${ }^{1}$ Department of Ophthalmology, Faculty of Medicine, Universitas Sriwijaya, Indonesia

*Corresponding author email: shaelva.lassa@gmail.com

\begin{abstract}
Introduction. Submacular hemorrhage is defined as the presence of blood in the potential space between retinal pigment epithelium (RPE) and neurosensory retinal in the macula. Pneumatic displacement is one of the management procedures that is shifting the bleeding under the macula by injecting gas. The purpose of writing this case report is to report Sub-macula Bleeding cases which are managed with Pneumatic Displacement.

Case Presentation. A 55-year-old woman, housewife, was living outside the city, came with complaints of a sudden blurred left eye since 2 weeks ago. At the ophthalmological examination, $612 \mathrm{pH}(-)$ right eye vision and 1/300 left eye vision were obtained. On examination of the anterior segment in the right and left eye the lens is cloudy with grade I nuclear morphology. The image of the right eye fundoscopy is within normal limits, whereas in the left eye a macula is found: reflex fovea (-) blood (+). The choice of therapy in this patient is carried out by Pneumatic Displacement by injecting C3F8 gas, which aims to shift the bleeding under the macula by injecting gas.
\end{abstract}

Conclusion. Pneumatic Displacement is a simple procedure, not too invasive, and the risk of intraocular complications is smaller. Pneumatic Displacement aims to shift blood from under the macula to other parts of the retina that are less vital for vision.

Keywords. submacula bleeding, treatment, pneumatic displacement

\section{Introduction}

Submacular hemorrhage is defined as the presence of blood in the potential space between retinal pigment epithelium (RPE) and neurosensory retinal in the macula. Submacular hemorrhage is an ocular disorder that can cause significant visual loss. ${ }^{1,2}$ 
Submacula hemorrhage is most common due to choroidal neovascularisation (CNV) and Age-related Macular Degeneration (AMD) which are the main causes of CNV. 1,2,3 Most studies report that AMD is $80 \%$ the main cause of CNV. Idiopathic Polypoidal Choroidal Vasculopathy (IPCV) is a recognized new thing that can cause submacular bleeding. This condition is a variation of choroidal neovascularization (CNV) and AMD. ${ }^{3,4}$

Management of Submacular Bleeding include vitrectomy, pneumatic displacement, intravitreal/subretinal tissue plasminogen activator (tPA) and intravitreal anti VEGF. Pneumatic displacement is one of the management procedures that is shifting the bleeding under the macula by injecting gas. $1,5-8$

The main benefit of this technique is to shift blood from under the macula to other parts of the retina that are less vital for vision. This action does not aim to eliminate the source of bleeding but only to save the macula from permanent damage by the blood underneath. The results of sharp vision are comparable between vitrectomy surgery and Pneumatic Displacement especially for moderate macular bleeding. Ideally, pneumatic displacement is done within 7 to 14 days to minimize permanent visual loss secondary to submacular bleeding. ${ }^{5-8}$

Bleeding Sub-macula with a duration of 2 weeks or less and good sharp vision when bleeding occurs has a good prognosis. Eyes with heavy bleeding in the fovea, expanding to more than 3 or more-disc areas, and eyes with AMD have poorer visual results. ${ }^{6,9}$

The purpose of writing this case report is to report Sub-macula Bleeding cases which are managed with Pneumatic Displacement.

\section{Case Report}

A woman, age 55, housewife, having address outside the city, went to the Palembang RSMH eye clinic on April 13, 2016. MR: 946902. Amnesis main complaint Left eye blurred suddenly since two weeks ago.

Travel history of the disease is Two weeks ago, sufferers complained that the patient's left eye suddenly ran away while sitting. Red eyes do not exist, see as flying objects and flashes of light do not exist, see as if there is no curtain, no pain.

Since three days ago, sufferers complained that the vision of the left eye was increasingly blurred, especially in the middle of the field of vision, without pain, red eyes were absent, seeing as flashes of light were absent, seeing as flying objects were absent, vision as if there were no 
curtain. Headache, nausea and vomiting do not exist. Patients do not seek treatment for their complaints.

Since one day ago, the sufferer felt that his vision was increasingly blurred and expanded, the patient then went to the local hospital and then was referred to Moh. Hoesin Palembang.

Past medical history is a history of trauma is denied, history of diabetes mellitus is denied, history of hypertension is denied, history of frequent bleeding is denied before.

Physical examination of generalist status are General Conditions: Good, Blood Pressure: 110/70 mmHg, Pulse: $82 \mathrm{x} /$ minute, Temperature: $36.7^{0} \mathrm{C}$, Respiration: $18 \mathrm{x} /$ minute.

Table 1. Ophthalmological status table

\begin{tabular}{|c|c|c|}
\hline & Right eye & Left eye \\
\hline Vision & $6 / 9 \mathrm{pH}(-)$ & $1 / 300$ \\
\hline TIO & $18,5 \mathrm{mmHg}$ & $18,5 \mathrm{mmHg}$ \\
\hline Eyeball position & \multicolumn{2}{|c|}{ Ortoforia } \\
\hline Eyeball Movement & Good in all directions & Good in all directions \\
\hline Palpebra & Quite & Quite \\
\hline Conjunctiva & Quite & Quite \\
\hline Cornea & Clear & Clear \\
\hline Front eye chamber & Medium, clear & Medium, clear \\
\hline Sliced & Good image & Good image \\
\hline Pupil & $\begin{array}{l}\text { Round, central, RC (+), Ø } 3 \\
\text { mm }\end{array}$ & $\begin{array}{l}\text { Round, central, RC (+), Ø } 3 \\
\text { mm }\end{array}$ \\
\hline Lens & Cloudy, Nuclear I & Cloudy, Nuclear I \\
\hline POSTERIOR SEGMEN & $\mathrm{RF}(+)$ & $\mathrm{RF}(+)$ \\
\hline Papil & $\begin{array}{l}\text { Round, firm boundary, } \\
\text { normal red color, c/d } 0.3, \mathrm{a} / \mathrm{v} \\
2: 3\end{array}$ & $\begin{array}{l}\text { Round, firm boundary, } \\
\text { normal red color, c/d } 0.3, \mathrm{a} / \mathrm{v} \\
2: 3\end{array}$ \\
\hline Macula & Fovea Reflexes (+) N & $\begin{array}{l}\text { Fovea Reflexes (-) } \\
\text { blood }(+)\end{array}$ \\
\hline Retina & Good blood vessel contour & Good blood vessel contour \\
\hline
\end{tabular}

Retinal drawing image

\begin{tabular}{|c|c|}
\hline OD & OS \\
\hline
\end{tabular}




\section{SRIWIJAYA JOURNALOF OPHTHALMOLOGY}

\section{बज्ञा}

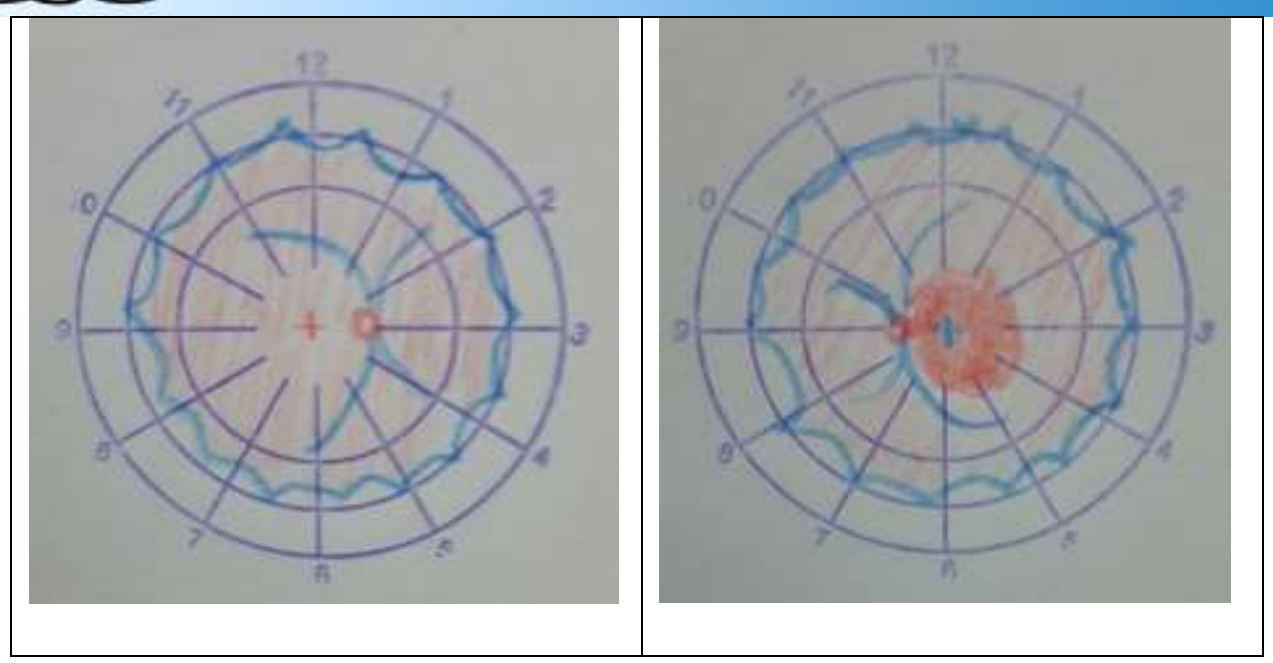

Fundus photo supporting examination

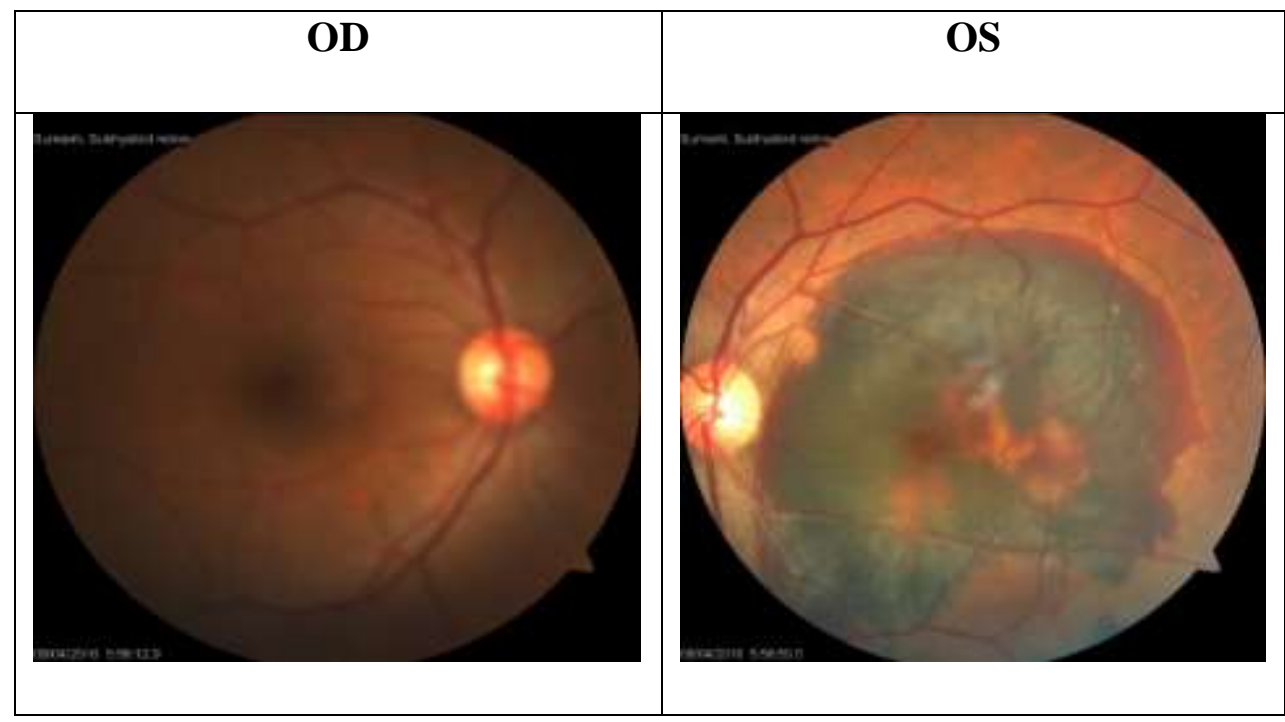

Pictures of OCT OD 

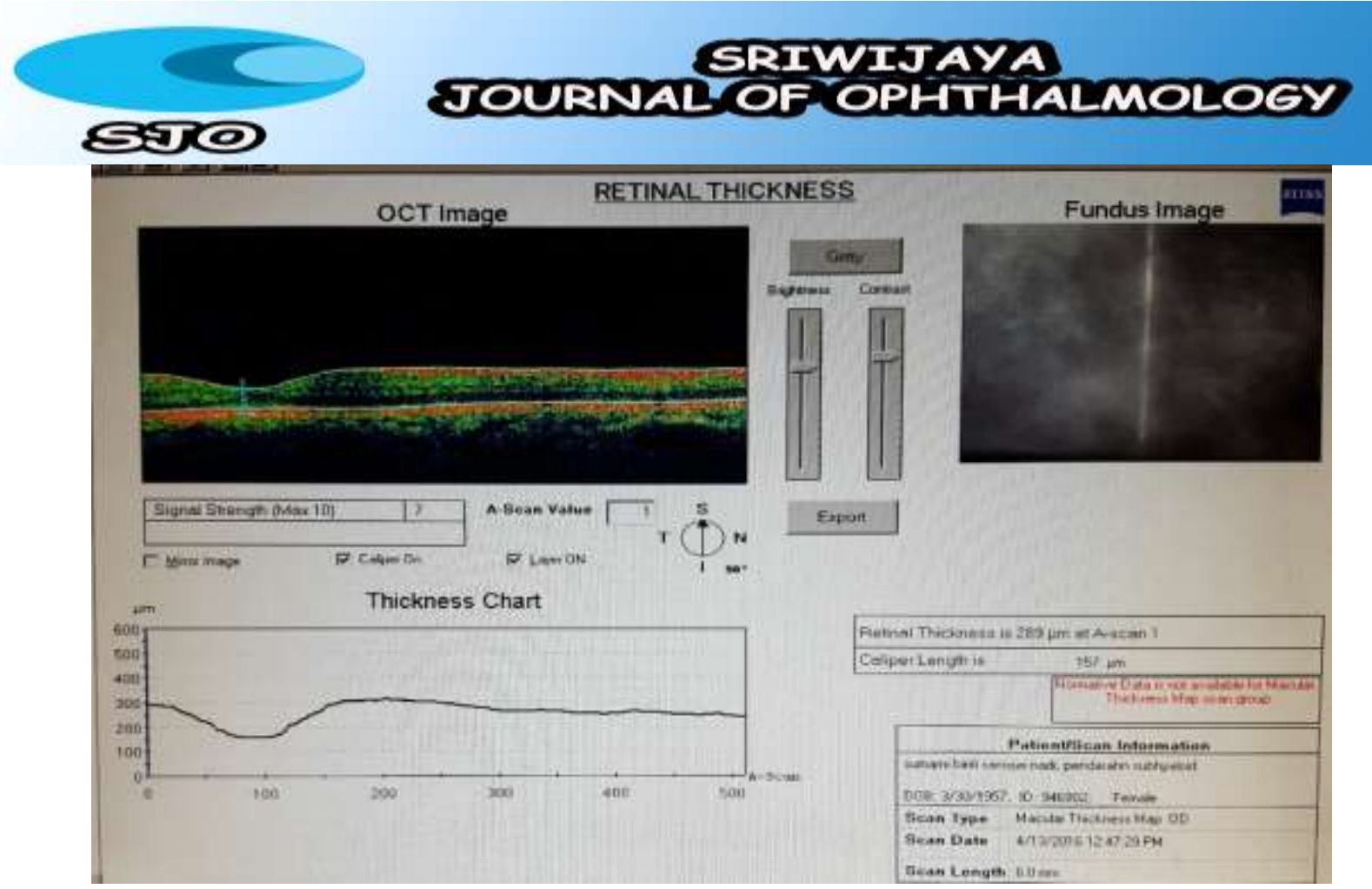

Impression: within normal limits

Pictures of OCT OD

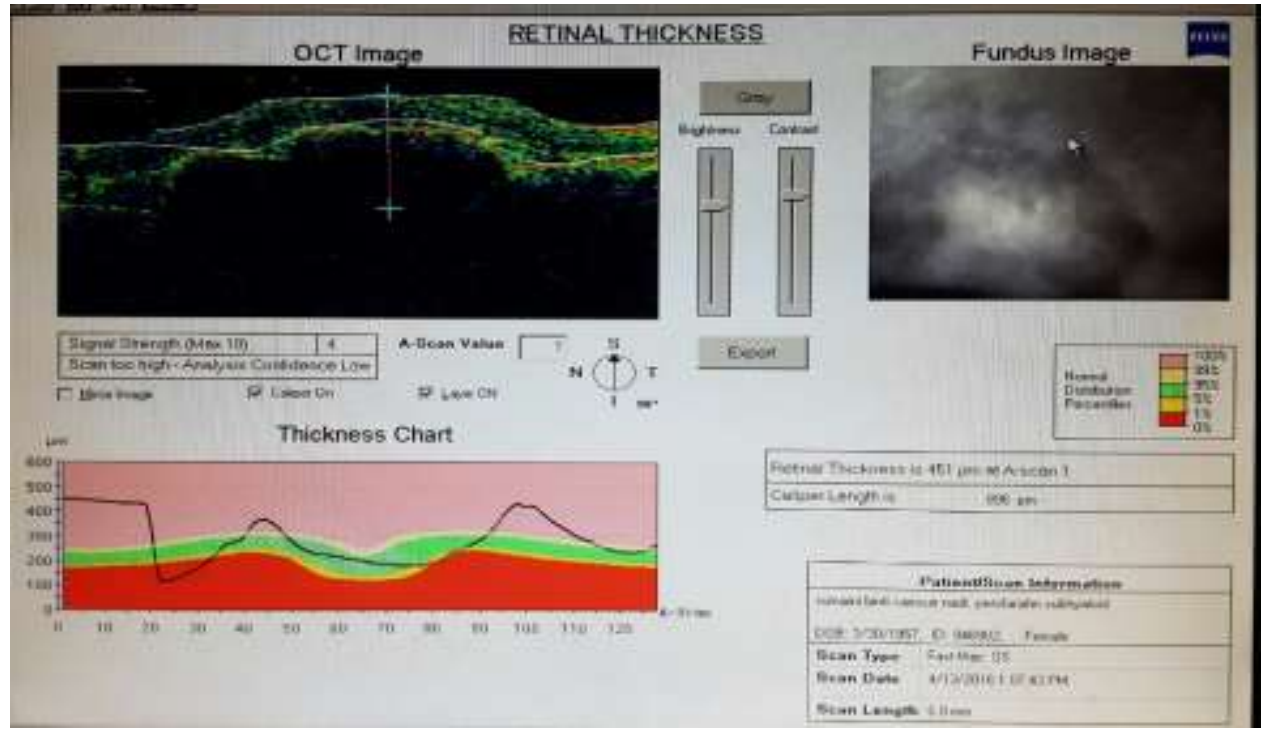

Interpretation: there appears to be an increase in hyporefectivity in the macula. Impression: blood in the submacular OS

Management is Informed Consent, Hospitalized, Pro Pneumatic Displacement OS, Pro Xray Thorax PA, Blood Check, Pro Internal Medicine Consul. The prognosis is Quo ad Vitam: Bonam, Quo ad Functionam: Dubia.

\section{Discussion}


The patient is a 55-year-old woman, living outside the city with a housewife's job, came with complaints of a sudden blurred left eye since, 2 weeks before being admitted to the hospital. From the history obtained blurred left eye when the patient is sitting, blurred vision without pain, red eyes are absent, seeing as a flash of light does not exist, seeing as a flying object is absent, vision as if there were no curtains, no history of trauma was denied. When it comes the patient complains that his left eye vision is increasingly blurred, without accompanied by pain and vision like a curtain closed.

The generalist examination was found to be within normal limits, and laboratory examination results were also within normal limits. At the ophthalmological examination, $612 \mathrm{pH}$ (-) right eye vision and 1/300 left eye vision were obtained. On examination of the anterior segment in the right and left eye the lens is cloudy with grade I nuclear morphology. The image of the right eye fundoscopy is within normal limits, whereas in the left eye a macula is found: reflex fovea (-) blood (+). Based on the history and clinical examination obtained, a diagnosis of Sub-macula Bleeding was made. And supporting examination carried out to establish the diagnosis that is examination of fundus photographs in the left eye obtained Sub-macula Bleeding.

In this patient who is 55 years old obtained a history of vision suddenly blurred while sitting. On the check of the Amsler grid, metamorphopsia was found. The cause of sub-macular bleeding in these patients is suspected to be due to choroidal neovascularization due to age related macular degeneration (AMD) because AMD usually occurs over the age of 50 years. The results of the laboratory examination did not get any abnormalities so that the causes due to blood disorders could be removed.

The hallmark of AMD is choroidal neovascularization (CNV). To establish a diagnosis of AMD it is necessary to have an FFA examination as a gold standard examination. However, FFA examination cannot be done because there is no available sodium flourensens.

Optical Coherence Tomography (OCT) examination can help show the macula layer, subretinal fluid, subretinal blood, and RPE elevation. In patients found sub-macula blood. Subsequent OCT examination to evaluate whether the sub-macula blood decreases.

The choice of therapy in this patient is carried out by Pneumatic Displacement by injecting $\mathrm{C} 3 \mathrm{~F} 8$ gas, which aims to shift the bleeding under the macula by injecting gas. The main benefit of this technique is to shift blood from under the macula to other parts of the retina that are less vital for vision. This action does not aim to eliminate the source of bleeding but only to save the macula from permanent damage by the blood underneath. This Pneumatic Displacement procedure is a simple, effective, not-too-invasive therapy in cases of sub-macular hemorrhage. 
The prognosis in this patient is quo ad functionam dubia due to extensive sub-macular hemorrhage of more than 3 disc areas and poor visual acuity that is only a wave of the hand when first arriving, but therapy is carried out 14 days after symptoms appear so that it is expected to minimize permanent visual loss secondary to bleeding sub-macula.

\section{Conclussion}

A case of Submacula Bleeding was reported in a 55-year-old woman. Diagnosis is made from history and physical examination and supporting examination. Management in these patients is Pneumatic Displacement.

Pneumatic Displacement is a simple procedure, not too invasive, and the risk of intraocular complications is smaller. Pneumatic Displacement aims to shift blood from under the macula to other parts of the retina that are less vital for vision. This action does not aim to eliminate the source of bleeding but only to save the macula from permanent damage by the blood underneath.

\section{References}

1. Retinal vein occlusion (RVO) guidelines. The Royal College of Ophthalmologists. London. 2015.Retina and Vitreous. American Academy of Ophthalmology. Canada. 20142015.

2. Gregory L. Skuta,MD. Retina and Vitreous. Section 12. Basic and Clinical Science Course. American Academy of Ophthalmology: 2014- 2015: p 8-14, 63-71,349-351.

3. Liu, Wu. Current Management of submacular hemorrhage in age-related macular degeneration. Int J. Ophthalmol, Vol.2, No.1. 2009. p 77-80.

4. Stephen J.Ryan, Vitrectomy For Removal of Submacular Hemorrhage,Retina, Third edition,Vol:3:2001,p:2573.

5. Mayron yanoff, jay.S, Duker, james.J, Pneumatic Displacement of Submacular hemorrhage,Ophthalmology,2009,p:1230.

6. Gopalakrishan, MaheshfrcsEd, et all, PNEUMATIC DISPLACEMENT OF SUBMACULAR HEMORRHAGE: Safety, Efficacy, and Patient Selection, Retina: March 2007 - Volume 27 - Issue 3 - pp 329-334.

7. Ekta Rishi, Lingam Gopal, Pukhraj Rishi, Sabyasachi Sengupta, and Tarun Sharm, Submacular hemorrhage: A study amongst Indian eyes,Indian J Ophthalmol. 2012 NovDec; 60(6): 521-525. 


\section{JOURNALOFOPHTHALMOLOGY}

G्गत

8. Sophie J. Bakri, MD, Management of Subretinal Hemorrhage,AMD Update,Ophthalmology Management,2012.

9. Po-Min Yang, MD; His-Kung Kuo, MD; Min-Lun Kao, MD; Yung-Jen Chen, MD; HsihHao Tsai, MD, Pneumatic Displacement of a Dense Submacular Hemorrhage with or without Tissue Plasminogen Activator, Chang Gung Med J Vol. 28 No. 12 December 2005.

10. Chen, GW and Moshfeghi AA. Surgical Management of Massive Submacular Hemorrhage. Retinasurgery Surgical update. April 2012. p 40-44.

11. Liesegang TJ, Skuta GL, Cantor LB. Fundamental and Principles of Ophthalmology. In: American Academy Of Ophthalmology. Section 2. San Fransisco, 2014-2015: p.27-28,7274.

12. Retinal Blood Flow. In: Anatomy and Physiology Retina. Chapter 1. Clinical Retina: 2002: p4.

13. Iscott and Laurent, F. Management of Submacular Hemorraghe. In Eyewiki, American Academy of Ophthalmology.

14. Robert J. Lowe, MD • Richard B. Rosen, MD • Ronald C. Gentile, MD, Treatment Options for Submacular Hemorrhage,Retinal Physician,June $6^{\text {th }}, 2011$.

15. Sukhpal Singh, Sandhu, Sridhar Manvikar, David Henry William Steel ,Displacement of submacular hemorrhage associated with age-related macular degeneration using vitrectomy and submacular tPA injection followed by intravitreal ranibizumab, Clinical Ophthalmology 2010:4 637-642.

16. G Mahesh, A Giridhar, Seshadri J Saikumar, A Elias. Intravitreal gas for submacular haemorrhage,Indian Journal of Ophthalmology,volume 3,2013, issue4:p:349-350.

17. Bozho Todorich, PhD, Harry W. Flynn,et al. Submacular Hemorrhage: Management Options and Literature Review ,Eye Wiki ,31 desember 2010.

18. Gene W. Chen, MD; and Andrew A. Moshfeghi, MD, MBA, Vitrectomy and subretinal rtPA are options to be considered,retina Today,The Vitreous and Choroid,April 2012.

19. Simone Donati, MD,Treatment of sub macular hemorrhages with t-PA: a review RetinaToday, 2006; 3(1).

20. Gene W. Chen, MD; and Andrew A. Moshfeghi, MD, MBA, Surgical Management of Massive Submacular Hemorrhage, Retina Today April 2012. 